Nađa S. Miljković ${ }^{1}$

https://doi.org/10.46630/phm.13.2021.30

Université de Niš

Faculté de philosophie

Département de langue et de littérature françaises

\title{
SYNONYMES COMME UN DES PROBLÈMES DE TRADUCTION DU FRANÇAIS VERS LE SERBE SUR L'EXEMPLE DE L'ACCORD DE CIEL OUVERT ET DES ACTES ANNEXES
}

\begin{abstract}
En partant du modèle théorique situationnel (dénotatif) de la traduction et du principe déquivalence fonctionnelle (CATFORD 1965), nous porterons notre attention particulière aux types de relations sémantiques, c'est-à-dire à la synonymie entre les termes juridiques français et serbes. Lorsque nous analysons l'original français et la traduction serbe de l'Accord de ciel ouvert et des actes annexes, malgré des instructions clairement définies dans le Manuel de traduction des actes juridiques de l'UE, il y a une incohérence de terminologie, ce qui conduit à une confusion dans l'interprétation des documents. Nous montrerons également que dans certains cas le traducteur n'a pas utilisé de solutions de traduction adéquates et que les significations des lexèmes donnés dans le contexte approprié ne sont pas suffisamment nuancées.
\end{abstract}

Mots-clés : traduction, synonymie, droit, langue française, langue serbe

\section{Introduction}

Dans l'analyse comparative des traductions de la terminologie juridique de différentes langues (les ouvrages consultés sont en serbe (KRSTIĆ 2008), anglais (CATFORD 1965) et français (CORNU 2005)), nous remarquons que le problème clé est de trouver des équivalents juridiques en raison des différences entre les systèmes juridiques. À savoir, Šarčević dans ses publications (ŠARČEVIĆ 2000 ; 2001) souligne que le dictionnaire juridique dépeint la civilisation, indiquant la complexité du dictionnaire par rapport à son niveau de progrès, ce qui rend létude de cette civilisation plus intéressante.

Gérard Cornu (2005) met l'accent sur la complexité de la traduction des textes juridiques due à l'existence du bilinguisme, qui doit être surmonté 1 nadjamiljkovic018@gmail.com 
au plus haut niveau. Catford (1965) insiste sur l'importance du terme « équivalent » lors de la traduction. Il définit la traduction comme « le remplacement du matériel textuel d'une langue (la langue de l'original) par le matériel textuel équivalent d'une autre langue (la langue de la traduction)» (CATFORD 1965 : 20). En conséquence, la plupart des théoriciens de la traduction de la seconde moitié du XX ${ }^{e}$ siècle, y compris John Catford, soulignent que « le principe fondamental de la théorie de la traduction est le principe de léquivalence fonctionnelle " (KRSTIĆ 2008 : 133). Selon Krstić, ce principe est également "la plus grande portée de la pensée théorique moderne sur la traduction » (KRSTIĆ 2008 : 136).

"Selon ce principe, dans la langue vers laquelle on traduit (la langue de la traduction ou la langue d'arrivée) il faut trouver des signes, c'est-à-dire des mots et la disposition de ces mots, qui correspondront en fonction aux signes de la langue à partir de laquelle il est traduit (langue originale ou langue de départ) » (KRSTIĆ 2008 :134).

De plus, il est extrêmement important pour la traduction correcte, car il met l'accent sur l'importance de transmettre les idées dans le contexte et l'esprit de la langue dans laquelle la traduction transfère les informations ce qui est garanti par des instructions clairement définies dans le Manuel de traduction des actes juridiques de l'UE (2021).

Dans son mémoire de master « Problèmes de traduction de la terminologie juridique du français vers le serbe à l'exemple des conventions européennes " Dragana Jovanović (2017) a traité le problème des relations sémantiques qui sétablissent lors de la traduction de documents juridiques. Examinant la traduction des conventions européennes du français vers le serbe et sa convenance, l'auteure traite de la monosémie, de la polysémie et de la synonymie avec une présence d'internationalismes dans le contexte de la terminologie juridique. Les recherches de Svetlana Jakimovska $(2013$; 2014) sont particulièrement importantes dans le domaine de la traduction de la terminologie juridique du français vers le macédonien et soulève ainsi de nombreux problèmes liés à la traduction de termes juridiques, dont l'ambiguité dans la langue.

Dans la suite de notre analyse, nous nous concentrerons sur l'un des problèmes de lexique - la synonymie, car l'analyse l'a indiqué comme une des difficultés sur le plan lexical. Notre hypothèse initiale est que la monosémie prédominait dans le langage du droit. De plus, l'intention des auteurs d'utiliser des mots sans ambiguité a été clairement mise en évidence lors de l'analyse.

Le corpus d'analyse comprend l'Accord de ciel Ouvert et des actes de mise en œuvre d'accompagnement des réglementations déterminées par l'Accord-cadre. Les documents sont disponibles dans le journal officiel de l'Union européenne EUR-Lex et sur le site du ministère de l'Intégration Européenne et de la Direction de l'Aviation Civile en Serbie. La traduction a été faite de la version anglaise vers le serbe. Cependant, nous attirons particulièrement l'attention 
sur le fait que l'accord et ses actes d'accompagnement sont disponibles dans les langues des fondateurs de l'Union européenne, comme indiqué par EUR-Lex :

"Les quatre langues officielles des États membres fondateurs, à savoir l'allemand, le français, l'italien et le néerlandais, bénéficient de la couverture linguistique la plus large. Pour les autres langues, vous trouverez les traductions de la législation en vigueur au moment de l'adhésion du pays en question et les textes adoptés après cette date. »

En partant du modèle théorique situationnel (dénotatif) de la traduction et du principe d'équivalence fonctionnelle (CATFORD 1965), nous porterons notre attention particulière aux types de relations sémantiques, c'està-dire à la synonymie entre les termes juridiques français et serbes. Ensuite nous avons effectué une comparaison de l'original et la traduction ayant pour le point de départ la consultation des dictionnaires bilingues et unilingues généraux comme celui de Putanec (1957) ou Larousse (2021) et juridiques tels que Juridictionnaire (2021), Francusko-srpskohrvatski ekonomsko-pravni rečnik (JANKOVIĆ ET ĐUROVIĆ 1969) et Rečnik pravnih termina (JOVANOVIĆ ET TODOROVIĆ 2004) ainsi que l'Encyclopédie juridique (1985).

\section{Synonymie des termes juridiques}

Lopposé de la polysémie est la synonymie, avec un signifiant et plusieurs signifiés. Cornu traite ce phénomène dans ses recherches, le mentionnant dans le chapitre Relations comparées (2005 : 173), où il examine la synonymie au sein de la relation par analogie, en citant ses deux caractéristiques : la dualité des signifiants et l'identité des signifiés. Ce qui signifie que pour une identité du signifié il y a plusieurs signifiants, cest-à-dire, termes ou lexèmes. Dans le langage du droit, il s'agit d'éliminer la synonymie (CORNU, 2005 : 173 -177), afin dobtenir la plus grande précision possible. Les deux grands groupes de synonymes cités dans les ouvrages sont :

1. Les synonymes absolus appartiennent au groupe des synonymes où l'un des deux termes qui composent une paire de synonymes peut changer l'autre et vice versa, quel que soit le contexte. La meilleure façon de vérifier les synonymes absolus est de remplacer un mot par un autre. Si un mot est relevé dans un contexte donné et que son synonyme est inséré sans aucun changement de sens, ce terme peut être appelé synonyme absolu. Bien qu'ils soient présents, il y en a un nombre très limité, nous allons donc nous concentrer davantage sur le deuxième type de synonymes approximatifs. Nous avons choisi cette approche après avoir analysé la littérature disponible et de nombreux exemples qui ont pratiquement montré que la synonymie absolue est impossible. Car, si nous prenons en compte la présence de contexte, les nuances qui contiennent différentes situations de discours et l'affirmation de l'auteur Dragićević (2010) 
selon laquelle la langue manque de lexèmes décrivant des termes existants tant dans le langage courant que professionnel, nous partageons cette vision de l'impossibilité de l'existence d'un grand nombre de noms identiques pour un terme possible, pour la même raison. ${ }^{2}$

2. Les synonymes partiels / approximatifs ou parasynonymes sont des mots qui ont des significations presque identiques, mais leur utilisation dans le contexte est différente. Le meilleur exemple, d’après Georges Cornu (2005), est un contrat, un accord écrit entre deux ou plusieurs parties en droit national ou international, nommé en serbe уговор. Il existe de nombreux lexèmes associés à ce terme, dont certains se trouvent dans le corpus : contrat, convention, pacte, arrêté, etc. Contrat et convention sont synonymes par certains auteurs, mais il y a une nuance de distinction dans le sens. Cornu définit le contrat comme un type de convention (accord) entre les parties, à condition que les parties établissent des droits et des obligations et $y$ adhèrent.

Par conséquent, selon le type du système juridique, le nombre de parties contractantes ${ }^{3}$, la nature de l'accord et de nombreux autres facteurs, il s'agira d'une convention, d'un accord, etc. et selon le contexte approprié, un seul de ces termes sera utilisé :

(1) «1. Les dispositions du présent accord et celles des actes visés à l'annexe I, dans la mesure où elles sont identiques en substance aux règles correspondantes du traité $\mathrm{CE}$ et aux actes adoptés en vertu de ce traité, sont, aux fins de leur mise en œuvre et de leur application, interprétées conformément aux arrêts et aux décisions de la Cour de justice et de la Commission européenne antérieurs à la date de signature du présent accord. $»^{4}$

(1) a) „1. С обзиром да су одредбе овог споразума и одредбе прописа наведених у Анексу I овог споразума у основи идентичне одговарајућим правилима Уговора Е3 и прописима који су усвојени у складу са Уговором E3, те одредбе се, у спровођењу и примени, тумаче у складу са релевантним решењима и одлукама Суда правде и Европске комисије које су донете пре датума потписивања овог споразума."

Ensuite, nous montrerons les synonymes les plus courants qui peuvent contribuer à des erreurs et à des omissions de traduction en cas de distinction insuffisamment claire des différences.

2 Des informations supplémentaires qui ont contribué à ce type de conclusion sont les exemples de synonymie absolue de Cornu, dont il ne cite qu'un exemple de ce qui est possible en termes de préjudice et dommage, mais il remarque dans la note que ce n'est pas non plus le meilleur exemple, car selon certaines analyses doctrinales. Bien que les deux termes signifient des dommages, le premier signifie toujours une partie du second terme (Cornu, 2005 : 173).

3 Les parties contractantes sont des personnes ou des institutions qui concluent un contrat.

4 Accord Multilatéral sur la création d'un espace aérien commun européen, article 16, 1.

5 Мултилатерални споразум о успостављању заједничког ваздухопловног простора, члан 16,1 . 


\section{1. ПОРЕ3}

Les termes taxe (plus souvent traduit en serbe par maкce) et impôt, tous les deux visibles dans le corpus sont traduits en serbe par le terme nope3. Bien qu'ils alternent dans les actes et dans l'Accord, le premier renvoie à la notion de recettes publiques de base que l'État collecte pour financer les dépenses publiques à tous les niveaux de gouvernement, ou dans les sphères économique et sociale, tandis que le second renvoie au type des recettes publiques qui sont l'équivalent monétaire des services fournis par des organismes publics à différents niveaux de gouvernement à des personnes physiques et morales :

(2) «2. Les États membres mettent tout en œuvre pour que l'entreprise commune bénéficie de l'exonération fiscale le plus large possible en ce qui concerne la TVA, les autres taxes et les droits d'accises. $»^{6}$

(2) a) „2. Државе чланице предузимају све расположиве мере како би обезбедиле Заједничком предузећу најшире могуће ослобађање од опорезивања нарочито у односу на ПДВ-а и друге порезе и акцизе. "7

(3) « 1 . En ce qui concerne les impôts et les droits de douane, le protocole sur les privilèges et immunités des Communautés européennes s'applique à l'entreprise commune à compter du 15 octobre 2008. $»^{8}$

(3) a) „1. Порези и царинске обавезе, наведене у Протоколу примењују се на Заједничко предузеће почев од 15. октобра 2008. године. "9

\section{2. ПОМОЋ}

Les termes aide et assistance ont le même sens, noмoh. Cependant, il existe deux types d'assistance différents. Le premier se situe dans le contexte de l'aide financière, tandis que le second renvoie à la notion de prestation de service, que nous pouvons voir dans sa seconde traduction comme опслуживање на земљи :

6 Règlement (CE) No 219/2007 du Conseil du 27 février 2007 relatif à la constitution d'une entreprise commune pour la réalisation du système européen de nouvelle génération pour la gestion du trafic aérien (SESAR), article 2, 2.

7 Правилник о преузимању европских прописа о успостављању Заједничког предузећа за развој нове генерације Европског система за управљање ваздушним саобраћајем (SESAR) („Службени гласник PC“, број 23/12), члан 2, 2.

8 Règlement (CE) No 1361/2008 du Conseil du 16 décembre 2008 modifiant le règlement (CE) no219/2007 relatif à la constitution d'une entreprise commune pour la réalisation du système européen de nouvelle génération pour la gestion du trafic aérien (SESAR), article 2 ter 9 Правилник о преузимању европских прописа о успостављању Заједничког предузећа за развој нове генерације Европског система за управљање ваздушним саобраћајем (SESAR) („Службени гласник PC“, број 23/12), члан 26 
(4) « 1 . Lorsque d'autres accords conclus entre deux ou plusieurs parties contractantes, tels que les accords d'association, contiennent des règles en matière de concurrence et d'aides d'État, ces règles s'appliquent entre les parties concernées. $»^{10}$

(4) a) „1. У случају када су правила о конкуренцији и државној помоћи обухваћена другим споразумима између две или више страна уговорница, као што су споразуми о придруживању, између ових страна уговорница примењују се ова правила. "11

\section{3. КОРИСНИК}

Les termes usager, bénéficiaire ou utilisateur sont traduits en serbe comme корисник. Cependant, dans le corpus, ces termes sont également remplacés lors de la traduction par le terme portant la signification consommateur, ce qui a conduit le traducteur à une traduction inadéquate, car il identifie le consommateur, quelqu'un qui achète des biens alors que l'utilisateur est orienté vers les services. Un autre synonyme présent est la clientèle. Ils sont sémantiquement les mêmes, mais la nuance dans les significations est la suivante: un usager est une personne qui utilise un service public qui est soit gratuit, soit à un prix qui ne couvre que les coûts alors que la clientèle est une personne qui paie pour un service ou marchandises et que cette personne est sous contrat. Usager et bénéficiaire sont directement interchangeables, tout comme le consommateur et la clientèle, cette paire ayant un moment commercial.

(5) « « usager d'un aéroport » : toute personne physique ou morale transportant par voie aérienne des passagers, du courrier et/ou du fret, au départ ou à destination de l'aéroport considéré; ${ }^{12}$

(5) „ а) корисник аеродрома (airport user) је правно лице или предузетник који је одговоран за превоз путника, поште и/или терета ваздушним путем до или од аеродрома; "13

(6) «RELATIONS AVEC LA CLIENTĖ LE $»^{14}$

10 Accord Multilatéral sur la création d’un espace aérien commun européen, article 14, 1.

11 Мултилатерални споразум о успостављању заједничког ваздухопловног простора, члан 14,1 .

12 Directive 96/67/CE du Conseil du 15 octobre 1996 relative à l'accès au marché de l'assistance en escale dans les aéroports de la Communauté, article 2.

13 Правилник о пружању услуга земаљског опслуживања на аеродромима „Службени гласник РС", број 61 од 10. јула 2015., члан 2.

14 Règlement (UE) 2015/340 de la Commission du 20 février 2015 déterminant les exigences techniques et les procédures administratives applicables aux licences et certificats de contrôleur de la circulation aérienne conformément au règlement (CE) no 216/2008 du Parlement européen et du Conseil, modifiant le règlement d'exécution (UE) no 923/2012 de la Commission et abrogeant le règlement (UE) no 805/2011 de la Commission. 
(6) „ а) ОДНОСИ СА КОРИСНИЦИМА УСЛУГА ”15

\section{4. ОДОБРЕЊЕ}

Les termes approbation, autorisation et agrément peuvent être traduits comme одобреньe. Bien que légères, parmi eux, nous pouvons rencontrer des nuances de significations. En termes d'approbation et d'autorisation, la première suit après l'achèvement d'un acte, c'est-à-dire une action tandis que l'autre est antérieure par rapport à la réalisation de l'acte donné. Alors que dans le cas de l'agrément par rapport à l'approbation, leur relation est de même nature, où le premier est antérieur ${ }^{16}$ et le second postérieur par rapport à l'acte accompli.

(7) «1. Le présent accord est soumis à ratification ou approbation par les signataires conformément à leurs procédures respectives. $»^{17}$

(7) a) „1. Овај споразум подлеже ратификацији или одобрену страна потписница у складу са њиховим домаћим законима. ”18

$(8)$ «4) [...] et des plans de vol déposés avant la première délivrance d'une autorisation du contrôle de la circulation aérienne; $»^{19}$

$(8)$ „ а) 4) [...] и планова лета поднетих пре првог издавања одобрења контроле летења; "20

(9) «3. [...] ainsi que les agréments des programmes de compétence d'unité et des plans de formation, délivrés en application des dispositions pertinentes de la législation nationale fondée sur la directive 2006/23/CE et en application des dispositions du règlement (UE) No 805/2011 sont réputés avoir été délivrés conformément au présent règlement. ${ }^{21}$

15 УРЕДБА КОМИСИЈЕ (ЕУ) БР. 2015/340 од 20. фебруара 2015. године о утврђивању техничких захтева и управних поступака који се односе на дозволе контролора летења и сертификате у складу са Уредбом (Е3) бр. 216/2008 Европског парламента и Савета, о изменама и допунама Спроведбене уредбе Комисије (ЕУ) бр. 923/2012 и престанку важења Уредбе Комисије (ЕУ) бр. 805/2011.

16 Il est également possible d'être postérieur, par exemple lors de la prise de fonction en tant que représentant diplomatique.

17 Accord Multilatéral sur la création d'un espace aérien commun européen, article 29, 1.

18 Мултилатерални споразум о успостављању заједничког ваздухопловног простора, члан $29,1$.

19 Règlement (UE) No 255/2010 de la Commission du 25 mars 2010 établissant des règles communes relatives à la gestion des courants de trafic aérien, article 2, 4).

20 Правилник о утврђивању правила за управљање протоком ваздушног саобраћаја („Службени гласник РС“, број 104/17) - преузео је Уредбу 255/2010, измењену и допуњену Спроведбеном уредбом Комисије (ЕУ) бр. 923/2012 и Спроведбеном уредбом Комисије (ЕУ) бр. 2016/1006, члан2, 4).

21 RĖGLEMENT (UE) 2015/340 DE LA COMMISSION du 20 février 2015 déterminant les exigences techniques et les procédures administratives applicables aux licences et certificats de contrôleur de la circulation aérienne conformément au règlement (CE) no 216/2008 du 
(9) a) „3. [...] као и одобрења процедура одржавања стручности у јединицама контроле летења и планова обуке, који су издати у складу са важећим одредбама националног прописа заснованог на Директиви 2006/23/Е3 или у складу са Уредбом (ЕУ) бр. 805/2011, издати у складу са овом уредбом. "22

\section{5. ОБРАЗАЦ}

Un autre exemple de traduction inadéquate qui a été réalisée précisément en raison du risque que la synonymie comporte est les termes formulaire et format qui ont été étaient traduits par le terme образац. Le premier terme est porteur de ce sens, mais le second ne peut être que облик, формат ayant la signification de la forme adoptée d'un document en aucun cas образац, utilisé par le traducteur, qui est un document réglementé pour une utilisation spécifique, pour lequel le traducteur a opté :

(10) «Les États membres remplacent les licences visées à l'article 7, paragraphe 1, par des licences conformes au format figurant à l'appendice 1 de l'annexe II du présent règlement au plus tard le 31 décembre $2015[\ldots] »^{23}$

(10) a) „ 4. 1. Државе чланице морају да замене дозволе наведене у члану 7. став 1. дозволама које су усаглашене са обрасцем који је утврђен у Додатку 1 Анекса II уз ову уредбу до 31. децембра 2015. године [...] "24

(11) «b) Tout élément ajouté sur, ou supprimé du formulaire doit être validé de manière claire par l'autorité compétente $»^{25}$

Parlement européen et du Conseil, modifiant le règlement d'exécution (UE) no 923/2012 de la Commission et abrogeant le règlement (UE) no 805/2011 de la Commission, article 7, 3.

22 УРЕДБА КОМИСИЈЕ (ЕУ) БР. 2015/340 од 20. фебруара 2015. године о утврђивању техничких захтева и управних поступака који се односе на дозволе контролора летења и сертификате у складу са Уредбом (Е3) бр. 216/2008 Европског парламента и Савета, о изменама и допунама Спроведбене уредбе Комисије (ЕУ) бр. 923/2012 и престанку важења Уредбе Комисије (ЕУ) бр. 805/2011, члан 7, 3.

23 Règlement (UE) 2015/340 de la Commission du 20 février 2015 déterminant les exigences techniques et les procédures administratives applicables aux licences et certificats de contrôleur de la circulation aérienne conformément au règlement (CE) no 216/2008 du Parlement européen et du Conseil, modifiant le règlement d'exécution (UE) no 923/2012 de la Commission et abrogeant le règlement (UE) no 805/2011 de la Commission, article 8, 1 .

24 УРЕДБА КОМИСИЈЕ (ЕУ) БР. 2015/340 од 20. фебруара 2015. године о утврђивању техничких захтева и управних поступака који се односе на дозволе контролора летења и сертификате у складу са Уредбом (Е3) бр. 216/2008 Европског парламента и Савета, о изменама и допунама Спроведбене уредбе Комисије (ЕУ) бр. 923/2012 и престанку важења Уредбе Комисије (ЕУ) бр. 805/2011, члан 8, 1.

25 Règlement (UE) 2015/340 de la Commission du 20 février 2015 déterminant les exigences techniques et les procédures administratives applicables aux licences et certificats de contrôleur de la circulation aérienne conformément au règlement (CE) no 216/2008 du Parlement européen et du Conseil, modifiant le règlement d'exécution (UE) no 923/2012 de la Commission et abrogeant le règlement (UE) no 805/2011 de la Commission, Annexe II, sous partie f. 
(11) a) „Надлежна власт мора да јасно одобри сваки унос или брисања у обрасиу. ${ }^{26}$

\section{6. НАДЗОР}

Dans le texte de départ nous retrouvons les termes supervision, contrôle, surveillance traduits comme надзор. Cependant, le traducteur, dans un souci de cohérence dans la traduction, impose la synonymie à un autre terme en traduisant aussi bien l'enquête comme надзор, ce que nous pouvons voir à partir du contexte donné que ce nest pas le cas :

(12) «Les États membres veillent au respect de l'application du présent règlement en procédant à des inspections, des enquêtes et des audits de sécurité; $»^{27}$

(12) a) „Државе чланице прате усаглашеност са овом уредбом помоћу инспекција, надзора и безбедносних провера. "28

\section{7. ТРОШАК}

La traduction des termes frais, coût, dépense et prix dans le corpus est трошак. Bien qu'ils semblent être des synonymes absolus, il existe une légère différence de sens. Le terme coût signifie la valeur de choses comme les produits et services, c'est-à-dire le montant du frais de son obtention ou de sa réalisation. Le terme prix désigne le montant qui fait référence à la valeur de la transaction (telle qu'une vente ou un échange) à laquelle ledit article est soumis. Le prix comprend non seulement les coûts réels, mais également d'autres facteurs tels que les revenus, les conditions du marché et autres éléments.

(13) « d) [...] établir et mettre régulièrement à jour le programme de travail global et annuel de l'entreprise commune, y compris une estimation des coûts du programme, et les soumettre au conseil d'administration ; ${ }^{29}$

(13) а) „ (д) израђује и редовно ажурира општи и годишњи про-

26 УРЕДБА КОМИСИЈЕ (ЕУ) БР. 2015/340 од 20. фебруара 2015. године о утврђивању техничких захтева и управних поступака који се односе на дозволе контролора летења и сертификате у складу са Уредбом (Е3) бр. 216/2008 Европског парламента и Савета, о изменама и допунама Спроведбене уредбе Комисије (ЕУ) бр. 923/2012 и престанку важења Уредбе Комисије (ЕУ) бр. 805/2011, Анекс II, подео ф.

27 Règlement (CE) No 2150/2005 de la Commission du 23 décembre 2005 établissant des règles communes pour la gestion souple de l'espace aérien, article 9.

28 Прилог 2 Правилника о преузимању прописа Европске уније о управљању ваздушним простором и флексибилном коришћењу ваздушног простора („Сл.гласник РС“, број 69/11), члан 9.

29 Règlement (CE) No 219/2007 du Conseil du 27 février 2007 relatif à la constitution d'une entreprise commune pour la réalisation du système européen de nouvelle génération pour la gestion du trafic aérien (SESAR), Annexe, article 7, 5. 
грам рада Заједничког предузећа, укључујући процену трошкова програма, које доставља Управном одбору; "зо

(14) «En tant qu'ils agissent dans le cadre du présent accord, les représentants, délégués et experts des parties contractantes ainsi que les fonctionnaires et autres agents sont tenus, même après la cessation de leurs fonctions, de ne pas divulguer les informations qui, par leur nature, sont couvertes par le secret professionnel, et notamment les renseignements relatifs aux entreprises et concernant leurs relations commerciales ou les éléments de leur prix de revient. $»^{31}$

(14) a) „Од представника, делегата и експерата страна уговорница, као и званичника и других службеника који делују према овом споразуму се захтева да, чак и када њихове функције престану, не откривају информације за које постоји обавеза чувања професионалне тајне, а посебно информације о предузећима, њиховим пословним везама или трошковима. "32

\section{8. ЗАКОН}

Les termes droit et loi sont traduits dans le corpus par le même terme закон. La traduction du terme droit est inapte, étant donné qu'il s'agit de право dont закон fait partie. En fait, un ensemble de plusieurs закон constitue право. Par extension le traducteur pratique pendant la traduction du terme législation une utilisation parallèle des termes закон et законски прописи. Cependant, ils nont pas la même signification car la législation (zakonodavstvo) est un ensemble des actes juridiques, pas un seul acte juridique. Le cas du terme acquis, qui est également traduit comme закон, est particulier en ce sens qu'il désigne les règlements juridiques de l'Union Européenne, qui ne peut être traduits que de manière descriptive en serbe, car les dictionnaires ne proposent pas de traduction de ce terme. Une autre solution peut être la traduction proposée par EVRONIM (2021) : acquis communautaire - правне тековине Заједнице.

(15) «3. Lorsque, conformément au paragraphe 2, une juridiction d'une partie contractante dont les décisions ne sont pas susceptibles d'un recours juridictionnel de droit interne nest pas en mesure de saisir la Cour de justice, ladite partie contractante transmet tout jugement prononcé par cette juridiction au comité mixte, qui prend position de manière à assurer l'interpré-

30 Правилник о преузимању европских прописа о успостављању Заједничког предузећа за развој нове генерације Европског система за управљање ваздушним саобраћајем (SESAR) („Службени гласник PC“, број 23/12), Анекс, члан 7, 5.

31 Accord Multilatéral sur la création d'un espace aérien commun européen, article 23.

32 Мултилатерални споразум о успостављању заједничког ваздухопловног простора, члан 23. 
tation homogène du présent accord. $»^{33}$

(15) a) „3. У случају када, у складу са ставом 2 овог члана, суд неке стране уговорнице, против чијих одлука не постоји правни лек према домаћем закону, није у могућности да се обрати Суду правде, сваку одлуку тог суда страна уговорница која је у питању ће да достави Заједничком комитету који ће да поступи тако да очува јединствено тумачење овог споразума. "34

\section{Conclusion}

Notre objectif de cette recherche était de montrer l'influence des relations sémantiques entre les mots en langage juridique. Dans le document, nous avons rencontré certaines omissions dans les dictionnaires (comme dans l'exemple de l'acquis) ou nous avons réussi à mettre en évidence les nuances dans la différence de sens (comme dans l'exemple de nорез). L'intention du traducteur de parvenir à la clarté et à la précision est perturbée par le recours fréquent aux synonymes dans le cas de termes qui semblent partager le même sens. Par exemple les termes loi, droit, législation et acquis appartiennent au champ sémantique de закон, pourtant ils se diffèrent par la partie de закон auquel ils se réfèrent. L'apparence évidente de synonymie chez les termes frais, cô̂t, dépense et celui du prix est de nouveau fautive, car il existe une différence entre le coût de revient qui comprend seulement les frais d'obtention ou de transaction et le prix qui contient en plus une marge par-dessus du coût de revient. Les termes approbation, autorisation et agrément peuvent être traduits comme un seul terme oдобреньe, ce que le traducteur a fait cependant, ils dife fèrent dans le moment où les actes sont réalisés.

La conclusion générale est qu'il existe un petit nombre de termes monosémiques dans le corpus analysé. En raison de l’ambiguité dominante de la langue, il est très important d'aborder la traduction de la langue de droit avec prudence et plus encore peut-être l'analyse des textes traduits. Si un mot synonyme est utilisé, cela peut conduire à une incompréhension intentionnelle ou non d'une norme et ainsi aboutir à une tentative d'abus du droit et à sa mauvaise application.

\section{Bibliographie}

CATFORD 1965: CATFORD, John Cunnison. A linguistic theory of translation. An essay in applied linguistic. Oxford: University Press, 1965.

CORNU 2005 : CORNU, Gérard. Linguistique juridique. Montchrestien : Collection

33 Accord Multilatéral sur la création d'un espace aérien commun européen, article 16, 3.

34 Мултилатерални споразум о успостављању заједничког ваздухопловног простора, члан $16,3$. 
Précis Domat, 2005.

DIRECTION DE LAVIATION CIVILE [en ligne] 2021: DIREKTORAT CIVILNOG VAZDUHOPLOVSTVA [en ligne] 2021: Директорат цивилног ваздухопловства [en ligne]. 2021. <http ://cad.gov.rs/>. 12.03.2021.

DRAGIĆEVIĆ 2010 : DRAGIĆEVIĆ, Rajna. Leksikologija srpskog jezika. Beograd: Zavod za udžbenike i nastavna sredstva, 2010. [orig.] ДРАГИЋЕВИЋ, Рајна. Лексикологија српског језика. Београд: Завод за уџбенике и наставна средства. 2010.

EUR-LEX [en ligne] 2021 : EUR-Lex. [en ligne]. 2021. <https://eur-lex.europa.eu/ content/help/faq/intro.html?locale $=$ fr $>$. 12.03.2021.

EVRONIM [en ligne] 2021 : Евроним. Multilingual terminology database [en ligne]. 2021. <http://prevodjenje.seio.gov.rs/evronim/index.php?jezik=engl>. 12.03.2021.

JAKIMOVSKA 2013 : JAKIMOVSKA, Svetlana. "Analyse comparative du phénomène de la synonymie dans les terminologies juridiques française et macédonienne ». Vestnik za tuje jezike L. 5, Št. 1-2 (2013) : 9-20. 12.03.2021.

JAKIMOVSKA 2014 : JAKIMOVSKA, Svetlana. Complex Lexical Unites in the Legal Language and their Translations from French into Macedonian and Vice Versa. Balkan Social Science, 2014.

JANKOVIĆ ET ĐUROVIĆ 1969 : JANKOVIĆ, Margita, ĐUROVIĆ, Radomir, JANKOVIĆ, Radoslav. Ekonomosko-pravni rečnik francusko-srpskohrvatski. Beograd : Međunarodna politika, 1969. [orig.] ЈАНКОВИЋ, Маргита, ЂУРОВИЋ, Радомир, ЈАНКОВИЋ Радослав. Економско-правни речник франиуско-српскохрватски. Београд: Међународна политика, 1969.

JOVANOVIĆ ET TODOROVIĆ 2004 : JOVANOVIĆ, Jasminka, TODOROVIĆ, Svetlana. Rečnik pravnih termina. Beograd : Savremena administracija, 2004. [orig.] ЈОВАНОВИЋ, Јасминка, ТОДОРОВИЋ Светлана. Речник правних термина. Београд: Савремена администрација. 2004.

JOVANOVIĆ, Dragana 2017 : JOVANOVIĆ, Dragana. Problemi prevođenja terminologije s francuskog na srpski jezik na primeru Evropskih konvencija. Thèse de master. Niš : Filozofski fakultet, 2017. [orig.] ЈОВАНОВИЋ, Драгана. Проблеми превођена правне терминологије с франиуског на српски језик на примеру Европских конвениија. Мастер рад. Ниш: Филозофски факултет, 2017.

JURIDICTIONNAIRE [en ligne] 2021 : Juridictionnaire. [en ligne]. 2021. < http:// www.cttj.ca/Documents/Juridictionnaire.pdf $>$. 12.03.2021.

KRSTIĆ 2008 : KRSTIĆ, Nenad. Francuski i srpski u kontaktu. Struktura proste rečenice i prevođenje. Novi Sad: Izdavačka knjižarnica Zorana Stojanovića Sremski Karlovci, 2008. [orig.] КРСТИЋ, Ненад. Франиуски и српски y контакту. Структура просте реченице и превођене.Нови Сад: Издавачка књижарница Зорана Стојановића Сремски Карловци, 2008.

LAROUSSE [en ligne] 2021 : Larousse - dictionnaire de la langue française. [en ligne]. 2021. <http://www.larousse.fr/dictionnaires>. 12.03.2021.

MANUEL DE TRADUCTION DES ACTES JURIDIQUES DE L'UE [en ligne] 2021 : PRIRUČNIK ZA PREVOĐENJE PRAVNIH AKATA EU [en ligne] 2021: 
Приручник за превођење правних аката ЕУ[en ligne]. 2021. <http:// www.mei.gov.rs/upload/documents/prevodjenje/prirucnik_prevodjenje 2016.pdf > 12.03 .2021$.

MINISTERE DE L'INTEGRATION EUROPEENNE [en ligne] 2021 : MINISTARSTVO ZA EVROPSKE INTEGRACIJE [en ligne] 2021 : Министарство за европске интеграције. [en ligne]. 2021. <http://www.mei.gov.rs/src/>. 12.03.2021.

ENCYCLOPÉDIE JURIDIQUE 1985: Правна енциклопедија 1 и 2. Београд: Савремена администрација, 1985.

PUTANEC 1957: PUTANEC, Valentin. Francusko-srpskohrvatski rječnik. Zagreb: Školska knjiga, 1957.

ŠARČEVIĆ 2000: ŠARČEVIĆ, Susan. New Approach to Legal Translation. The Hague: Kluwer Law International, 2000.

ŠARČEVIĆ 2001: ŠARČEVIĆ, Susan. Legal translation : Preparation for Ascension to the European Union. Rijeka: Faculty of Law, 2001.

\section{Sources}

ACCORD MULTILATÉRAL entre la Communauté européenne et ses États membres, la République d'Albanie, l'ancienne République yougoslave de Macédoine, la Bosnie-et-Herzégovine, la République de Bulgarie, la République de Croatie, la République d'Islande, la République du Monténégro, le Royaume de Norvège, la Roumanie, la République de Serbie, et la Mission d’administration intérimaire des Nations unies au Kosovo (1) sur la création d'un espace aérien commun européen. https://eur-lex.europa.eu/resource.html?uri=cellar:e233becd-52bd-482f-8741-b804549c5ebe.0009.02/DOC_2\&format=PDF

Мултилатерални споразум између европске заједнице и њених држава чланица, Републике Албаније, Босне и Херцеговине, Републике Бугарске, Републике Хрватске, Бивше Југословенске Републике Македоније, Републике Исланд, Републике Црне Горе Краљевине Норвешке, Румуније, Републике Србије и Мисије Привремене Управе Уједињених Нација на Косову о успостављању заједничког европског ваздухопловног подручја http://cad.gov.rs/upload/o_nama/Multilateralt ni\%20sporazum\%2019.06.07.pdf

Имплементација европских прописа садржаних у анексу I ECAА споразума у домаће законодавство http://cad.gov.rs/upload/regulativa/predlozi_proe pisa/Implementacija $\% 20$ evropskih $\% 20$ propisa $\% 20$ sadrzanih $\% 20 \mathrm{u} \% 20$ Aneksu\%20I\%20ECAA\%20sporazuma\%20u\%20domace\%20zakonodavstvo.pdf 
Нађа Миљковић

\section{СИНОНИМ КАО ЈЕДАН ОД ПРОБЛЕМА ПРЕВОБЕЊА СА ФРАНЦУСКОГ НА СРПСКИ ЈЕЗИК НА ПРИМЕРУ СПОРАЗУМА О ОТВОРЕНОМ НЕБУ И ПРАТЕКИХ АКАТА}

Полазећи од ситуативног (денотативног) теоријског модела превођења и принципа функционалне еквиваленције (CATFORD 1965), посебну пажњу усмеравамо на типове семантичких релација тј. синонимију између француских и српских правних термина. Приликом упоређивања француског оригинала и спрског превода, упркос јасно дефинисаним упутствима у Приручнику за превођење правних аката ЕУ, јавља се недоследност терминологије што доводи до неподударности и забуна у тумачењу докумената. Такође показујемо да преводилац у одређеним случајевима није употребио адекватна преводна решења и да значења датих лексема у одговарајућем контексту нису довољно изнијансирана.

Клучне речи: превођење, синонимија, право, француски језик, српски језик 